\title{
I Just Pulled Myself Together and Realised I had to be Responsible: Adolescents' Experiences of Having a Friend Who Self-Harms
}

\author{
Sarah Hall ${ }^{1}$ (D) Yvonne Melia $^{2}$
}

Accepted: 27 May 2021 / Published online: 10 June 2021

(C) The Author(s), under exclusive licence to Springer Science+Business Media, LLC, part of Springer Nature 2021

\begin{abstract}
Background Self-harm usually begins during adolescence and adolescents that self-harm most commonly confide in friends, yet to date, there is little research from the friend's perspective.

Objective This qualitative study explores adolescents' experiences of what it is like to have a friend who self-harms by cutting and what this experience means for friendship, the wider peer group and psychological well-being.

Methods Semi-structured interviews were conducted face-to-face with a community sample of eight females aged between 13 and 18 years, living in England. Interpretative Phenomenological Analysis was used to analyse the data.

Results Four superordinate themes emerged: desperately searching for meaning, I will be there at all costs, too hot to handle and identification. Adolescents were concerned about escalations in their friends' behaviours and felt a sense of duty to help, but the majority experienced a dilemma as to whether to disclose to others and all reported some form of distress.

Conclusions The results highlight the important, yet complex nature of friendship in this context. Friends play a key role in supporting adolescents who self-harm but need greater support managing this role and the effects. Schools/colleges should educate young people about self-harm to increase their knowledge and skills in relation to supporting a friend with this issue. Furthermore, they should promote environments for talking about mental health openly to give young people increased opportunities for help-seeking.
\end{abstract}

Keywords Self-harm · Adolescence $\cdot$ Friendship $\cdot$ Peers $\cdot$ Qualitative $\cdot$ Cutting

Sarah Hall

sarah.hall@combined.nhs.uk

Yvonne Melia

yvonne.melia@staffs.ac.uk

1 Clinical Psychologist, The Darwin Centre, Queens Road, Stoke-on-Trent ST4 7LF, UK

2 Clinical Psychologist, The Science Centre, Staffordshire University Doctorate in Clinical Psychology, Leek Road, Stoke-on-Trent ST4 2RU, UK 


\section{Introduction}

Young peoples' mental health is high on the UK public health agenda and schools and colleges have an increasing role to promote positive well-being and provide support to young people with mental health needs. Self-harm in particular is said to be on the rise, with a recent study finding a 68\% increase in the incidence rate among girls aged 13-16 years between 2011 and 2014 (Morgan et al., 2017). However it appears to be a behaviour that remains largely hidden from services, as very few episodes of self-harm result in hospital presentation (Madge et al., 2008), especially if the method used is cutting (Hawton et al., 2002). A recent systematic review concluded that up to half of adolescents who self-harm do not seek help and of those that do, they prefer to seek support from friends rather than from professionals (Rowe et al., 2014). This is not necessarily surprising given that adolescence is a time when peer relationships become particularly important for companionship, intimacy and emotional support (Bukowski et al., 1998). Despite this, little is known about the friend's experience of being the confidant, which may be important given that friends of those who self-harm have been identified as being vital for providing support and aiding contact with professional help (Idenfors et al., 2015).

\section{Self-Harm and Adolescence}

Self-harm has been defined as any act of self-poisoning or self-injury by an individual, irrespective of their motivation (NICE, 2013). Although found to be the strongest predictor of suicide (Sakinofsky, 2000), empirical evidence suggests the main function of self-harm is to regulate emotions (Klonsky, 2007). However, it appears that different methods may have different motivations as Rodham et al. (2004) found that more individuals who took overdoses indicated they wanted to die than those who cut themselves. Methods include cutting, burning and head-banging (Klonsky \& Olino, 2008), with cutting deemed as the most common form of self-harm (Rowe et al., 2014), particularly in community samples (Madge et al., 2008).

The World Health Organisation (WHO) defines an adolescent as anyone between the ages of 10 and 19 (WHO, 2018) and self-harm usually begins during this period. It has been found to have a prevalence rate of 17.2\% among adolescents (Swannell et al., 2014), with $7.8 \%$ of young people across Europe reporting repetitive self-harm (Brunner et al., 2014). However, these figures may be under reported given that few young people who self-harm actually disclose it (Whitlock et al., 2006). Furthermore, those who do most commonly turn to their friends for support (Rowe et al., 2014), so it may remain hidden within friendships whilst unknown to services and significant others, such as family and school. Most research indicates self-harm is more prevalent in adolescent females than males (Madge et al., 2008).

\section{Disclosure of Self-Harm to Friends}

Many adolescents do not seek help for self-harm for fear of being stigmatised (Fortune et al., 2008a) or considered attention-seekers by others (Heath et al., 2011). However, research suggests that disclosure can be positive as concealing a stigmatising characteristic or behaviour from family and friends is associated with damaging consequences for the 
individual, including negative views about oneself (Pachankis, 2007). Among university students, friendship quality has been found to be positively associated with disclosure of self-harm (Armiento et al., 2014).

However, Smith (2015) found that discussing problems with a friend may be to the detriment of the recipient's own emotional well-being. Co-rumination, described as an excessive discussion of problems within a relationship (Rose, 2002), may explain this. Rose et al. (2007) found that for females, co-rumination led to increases in symptoms of depression and anxiety, although they also experienced increases in closeness and friendship quality. In relation to self-harm, Reichardt (2016) found that young people who disclosed to a friend experienced comforting feelings through mutual understanding; however this was sometimes associated with negative experiences for the friend, such as feeling responsible for their peer's self-harming behaviours. Although this study was limited by its small sample size, Hasking et al. (2015) also found negative outcomes associated with disclosures to peers. These included using more avoidance strategies, such as ignoring the problem or blaming themselves, compared to those who disclosed to adults, and encouragement of self-harm in others.

The idea that disclosure of self-harm may encourage it in others is supported by other research; for example, Hawton et al. (2006) found an association between awareness of a friend's self-harm in the previous year and higher rates of self-harm in peers. In addition, Claes et al. (2010) found those who engaged in self-harming behaviours also had more friends who did the same and there is evidence that those who self-harm are more likely to seek help from others who do (Fortune et al., 2008b). However, it is not clear whether those who self-harm are drawn to others doing the same or whether they are more likely to learn to do it as a coping strategy through exposure. Furthermore, it could be that having an awareness of someone else's self-harm means one is more likely to seek support from them due to thinking they may be more empathic, or to achieve a sense of belonging within their peer group.

\section{UK Context}

As an individualistic country, people in the UK tend to value privacy, to be self-reliant and view their identity as being independent from the wider group or society. It is perhaps not surprising therefore, that much self-harm remains hidden and that the dominant view of its function is that it regulates internal emotional states, rather than being an act of communication within its social context. Although there has been evidence of this found within inpatient settings (e.g. Taiminen et al., 1998), within community settings this has been largely overlooked. However, given the evidence that disclosure of self-harm to peers may lead to both positive and negative outcomes for the friend, self-harm may have much more of an interpersonal function and effect than previously known.

\section{Rationale for Study}

Existing research regarding self-harm amongst friends in adolescence is largely quantitative and tends to focus on factors that influence or predict self-harm amongst peers, such as an individual's own engagement in this behaviour (Prinstein et al., 2010; You et al., 2013). The views and experiences of friends are largely overlooked, as only a small number of studies have sought this through qualitative interviews. These studies (Fisher et al., 2017; Yip et al., 2002) found some similarities in relation to the support role of the friend; for 
example, both found friends provide emotional support to peers. However, samples were limited by size (Yip et al., 2002), age range and to those who had sought help (Fisher et al., 2017) and neither study was conducted in the UK. Therefore, there is a need for a better understanding of UK adolescents' experiences of having a friend who self-harms and what this means for their friendship, wider peer group and well-being. This is important as findings may inform future practice in relation to prevention and intervention for self-harm at the community level, particularly for schools and colleges. Based on previous research, is hypothesised that the friends of adolescents who self-harm are likely to play a key role in supporting them with this issue and this role may have a positive impact on their friendship, however, this is likely to be at an emotional cost to themselves.

\section{Research Aims}

The aims of this study were to:

- Explore the experiences of adolescents who have a friend who self-harms.

- Understand what self-harm means for the young person, their friendship experiences and wider peer group.

\section{Research Questions}

1. How do adolescents make sense of having a friend who self-harms?

2. What does self-harm mean for their friendship, wider peer group and own well-being?

\section{Method}

\section{Research Design}

A qualitative design was employed using semi-structured individual interviews and Interpretative Phenomenological Analysis (IPA). IPA was chosen because it fitted well with the aims of the study; it involves detailed exploration of an individual's personal lived experience of a particular phenomenon, which takes priority over theoretical preconceptions (Smith \& Osborn, 2015). Thus, reflexivity and attention to personal biases and assumptions are vital so that the researcher can remain faithful to participants' lived experience. IPA is also suitable for researching certain topics that are complex, ambiguous and emotionally laden (Smith \& Osborn, 2015), so very relevant to self-harm.

\section{Research Team}

The first and second authors made up the research team. The first author was a female Trainee Clinical Psychologist undertaking a professional doctorate at Staffordshire University at the time of the research and the second author, a female Clinical Psychologist working as a tutor on the professional doctorate course at Staffordshire University; both with knowledge and expertise in working with young people who self-harm. The researchers had no relationships with study participants prior to the research. The first 
author carried out the interviews and coded the data and will therefore be referred to as 'the researcher'. Participants were informed of the researcher's credentials.

\section{Recruitment}

Schools, colleges and young people's services across the North West of England, including emotional well-being services and youth clubs, were contacted about the research. Eventually, two schools and a charity, which supports the emotional health of young people through a variety of activities and therapies, agreed to support the research by promoting it to young people. At one school, staff spoke directly to pupils they knew were eligible. Figure 1 illustrates the recruitment process and highlights that six of the schools who declined to take part did so, either due to an adolescent population talking about self-harm or because they feared parents may worry that self-harm was a problem at their school.

To be eligible for the study, participants needed to be between 13 and 18 years of age, have a friend who currently, or within the last six months, self-harmed by cutting and were able to speak English well enough to take part in an interview. Cutting was selected as it is the most common form of self-harm in the community (Madge et al., 2008) and thus, seemed most relevant to the sample being targeted for this study. Recruitment took place between September 2018 and February 2019.

Fig. 1 Flow diagram of recruitment process

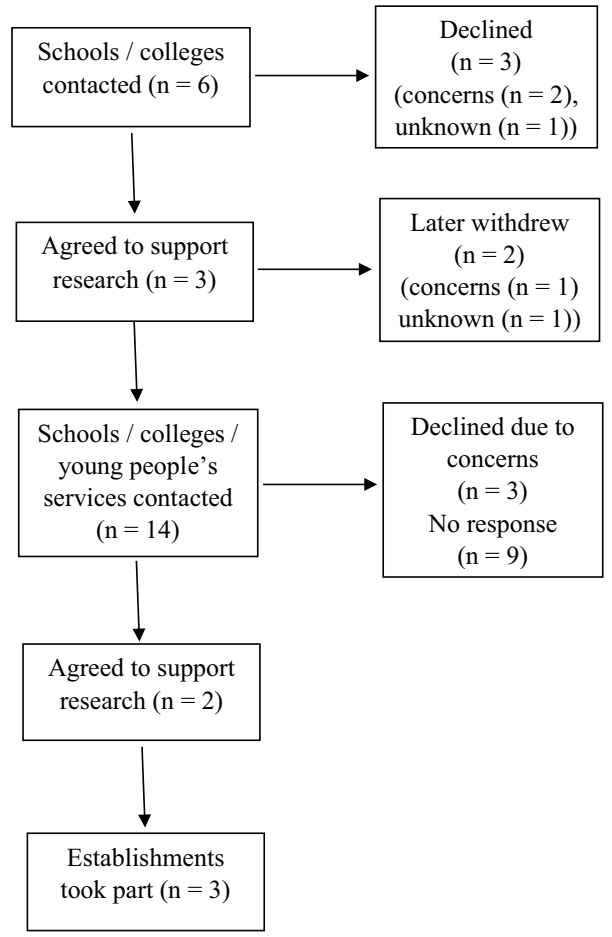




\section{Participants}

Eight females aged between 13 and 18 years, with a mean age of 15.5 years, took part in this study. Two additional young people agreed to take part but did not attend the interview; upon follow up one gave no reason, the other was absent due to family difficulties and unable to re-arrange. Participant demographic information is shown in Table 1.

Five of the participants became friends with the person they spoke about at high school; one at college and two at primary school. All described their friendship as 'close' or 'strong' before finding out about their friends' self-harm and had been friends for a year or more. In relation to the wider peer group, this was only relevant for four of the participants; for the others, people in their wider group were either not aware (one participant), were not part of a wider group (two participants) or others knew but no impact on the group was noticed (one participant).

\section{Procedure}

Interviews were conducted face-to-face by the researcher at the schools, the young people's service and a local youth club. For all interviews, including those with young people under 16 years of age, the researcher ensured there was another adult present in the building who was aware of the interview and its context. An interview schedule consisting of 8 questions was used, informed by the aims of the study. These were produced by drawing upon existing research in the area (e.g. Fisher et al., 2017) and through discussion amongst the authors. Examples of questions asked were 'can you tell me how you first found out about your friend's self-harm?', followed by 'looking back, what did self-harm mean to you then?', 'what does self-harm mean to you now?', 'could you describe the nature of your friendship after your friend told you about their self-harm?'. Interviews were audiorecorded and transcribed verbatim by the researcher. Interviews lasted between 16 and $30 \mathrm{~min}$, excluding additional questions about risk.

\section{Analysis}

Due to its idiographic focus, IPA requires a detailed examination of every case. Firstly, the researcher read the transcripts several times in order to immerse themselves in the data. Whilst doing this they noted their initial thoughts. Next, the researcher focused on distinct chunks of the transcripts to identify emerging themes within the data.

Table 1 Participant demographic information

\begin{tabular}{llllllll}
\hline No & Pseudonym & Gender & Ethnicity & Age & Gender of friend & Age of friend & Ethnicity of friend \\
\hline 1 & Christine & Female & White British & 14 & Female & 14 & White British \\
2 & Ann & Female & White British & 15 & Female & 15 & White British \\
3 & Jodie & Female & Mixed race & 13 & Female & 14 & White British \\
4 & Alex & Female & White British & 13 & Male & 12 & White British \\
5 & Cara & Female & White British & 16 & Female & 15 & Mixed race \\
6 & Amy & Female & White British & 18 & Female & 18 & White British \\
7 & Sally & Female & White British & 18 & Female & 18 & White British \\
8 & Rachel & Female & White British & 17 & Female & 17 & White British \\
\hline
\end{tabular}


Transcripts were then re-read to ensure the identified themes reflected a participant's words and thoughts as well as the researcher's interpretation.

All the identified themes were typed into a list in chronological order and entered into a spreadsheet in order to map out themes. Following this, the researcher looked for patterns within participants and began to cluster related themes together using colour coding. Once all transcripts had been analysed in the same way, the researcher looked for patterns across participants, producing emerging superordinate and subordinate themes, eventually typed into a list. From this the master table of themes was produced, which mostly included those that were well supported by the data (present for half or more of the participants). However, given the idiographic focus of IPA, one additional theme was included as it stood out as being of particular importance to an individual; she continually referred to it and it heavily related to how she made sense of her friend's self-harm.

\section{Analysis Credibility}

In qualitative research reflexivity and reflection on the researcher's position and research process are important (Yardley, 2000). The researcher took a social constructionist position which proposes that there is not one truth or a single reality; a person's reality is co-constructed through social processes that take place in historical and cultural contexts (Berger \& Luckmann, 1996). Thus, there are multiple ways of seeing the world and understanding an experience.

IPA involves a process known as a double hermeneutic, that is, the researcher tries to interpret the participant's interpretation of their experiences (Smith \& Osborn, 2008). Therefore, it is important for researchers to reflect on their own biases and understandings to allow participants' own experiences to emerge. The researcher has worked with young people in school, community and health settings, both individually and systemically, alerting them to the potential implications for this population of having a friend who self-harms. Although biases such as this cannot be eliminated, it has been proposed that researchers can bracket them in order to maintain objectivity (Koch \& Harrington, 1998). However, there is an argument that one can never truly be separated from their ongoing experiences and understanding a phenomenon is only possible because of preunderstandings, not in spite of them (Rabinow \& Sullivan, 1987); hence why the double hermeneutic is central to IPA (Smith \& Osborn, 2008).

However, to make the research process more rigorous, a data trail was kept of how emerging themes were established from transcripts, ensuring transparency, and a reflective diary was used which included notes about decisions regarding the research process and about interpretations, to consider when they may have been influenced by the researcher's own biases and experiences. Furthermore, cross-validation of interpretations was undertaken by presenting excerpts of transcripts to peers at a specialist IPA group, allowing for further consideration of any bias. However, it is acknowledged that in IPA the purpose is to offer one of many possible interpretations and therefore the aim of this validity check was to ensure credibility of the final account, rather than to prescribe a 'singular, true account' (Osborn \& Smith, 1998). Participant validation was not undertaken as this can be contentious in IPA because it conflicts with the double hermeneutic. Webb (2003) argues that even if a participant disagrees with the researcher's interpretation of the data, it does not invalidate the interpretation, it merely adds another version. 


\section{Access to Data}

The researcher takes responsibility for the integrity of the data and the accuracy of the data analysis.

\section{Results}

The aim of the analysis was to offer insights into participants' experiences of having a friend who self-harms. Table 2 shows the four superordinate and eight subordinate themes identified within the data.

Themes are described below with supporting quotations from transcripts.

\section{Superordinate Theme 1: Desperately Searching for Meaning}

Nearly all participants desperately wanted to make sense of their friend's self-harm; there was a sense that they needed it to be clear in their minds.

"Well self-harm I thought it was like, obviously it is something that can kill you, erm, but like there's, I just thought like, why is it in this world, like why does it have to be here, why do people do this..." (Christine, age 14)

Christine's repetition of the word 'why' indicates she was wrestling with the concept of self-harm, searching for meaning about something that seems senseless. She was struggling to reconcile the need for something so destructive to exist.

Jodie thought that her friend was compelled to do it, perhaps because it made it easier to accept.

"She knew not to do it again but she like, she couldn't help doing it again, she had to do it again, if you know what I mean." (Jodie, age 13)

Rachel initially battled with the intent behind it, but after more exposure she had a clearer picture.

Table 2 Table of themes

\begin{tabular}{lll}
\hline Superordinate theme & Subordinate theme & Present in participant(s) \\
\hline Desperately Searching for Meaning & & $1,2,3,5,6,7,8$ \\
I will be there at All Costs & I am not going to quit & $1,2,3,4,5,6,8$ \\
& It buried up inside me & All \\
Too Hot to Handle & This is not going to end well & $1,2,4,6,7,8$ \\
& I will say nothing to anyone unless I need to & $2,3,4,5,6,7,8$ \\
& Stop please & $3,4,5,6,7,8$ \\
Identification & Not the person I knew & $1,3,4,6,7,8$ \\
& I know exactly where you are coming from & $4,6,7,8$ \\
& Feeling invalidated & 7 \\
\hline
\end{tabular}


"The first time it happened it was kind of like, it was a way of causing pain but not dying, like wanting to die but not wanting to leave life behind... When it started happening kind of more often, I just saw it was a coping mechanism." (Rachel, age 17)

Most of the young people realised other issues were underlying their friend's self-harm and viewed it as a way to deal with internal pain.

"It still means that, you know, something harrowing's happening mentally." (Amy, age 18)

However, Sally's experience was quite different as over time she became annoyed with her friend, believing her self-harm was disingenuous and more to do with the social context.

"As time went on it just felt more and more like she was just attention seeking and then doing it because I was doing it..." (Sally, age 18)

\section{Superordinate Theme 2: I Will be There at All Costs}

There was a strong sense these young people would do anything for their friend. This included suppressing their own feelings in order to regulate their friends', meaning all experienced their own distress.

\section{I am not Going to Quit}

Nearly all participants took it on as their duty to be there for their friend, providing continuous support such as talking and listening. They dismissed their own feelings because it was more important for them not to give up on their friend.

"You've sort of just got to not be there constantly, but you've always got to be a shoulder..." (Amy, age 18)

“...but I'm not gonna quit, there had been nights where I thought no, this is my friend, I need to just sort of suck it up, you know." (Amy, age 18)

"She needs support and you know like, a calming friend who she can turn to normally... I'm always there to support her when she needs me and whenever she doesn't want me, I'll still support her through it." (Ann, age 15)

Ann's reference that she would support her friend even when she may reject her emphasises the lengths participants were willing to go to.

For Alex, her own needs were secondary to her responsibility; she needed to 'watch over' her friend, illustrating that she saw it as her duty to prevent anything bad from happening to him. This meant she was in a state of high alert whenever they were together.

"I just pulled myself together and realised I had to be responsible." (Alex, age 13)

"It makes me feel like I need to watch over him when we're all hanging out because

I'm the only one who knows about it." (Alex, age 13)

In three of the four cases where the wider friendship group were aware, the responsibility extended to them. They held a united front against self-harm.

"Like, we'd always talk to her and like we always told her that if she needs someone to talk to, like we'd always be there for her." (Jodie, age 13)

"You can tell us what's gone on instead of self-harming..." (Cara, age 16) 
"We all kind of supported each other, almost like a camp, like a group, but without the counsellors." (Rachel, age 17)

Rachel's quotation demonstrates how members of her group joined together to support one another, sharing the responsibility, which may have lightened the load for Rachel.

\section{It Buried up Inside me}

All participants were weighed down by their friend's self-harm, leading to their own anguish. Feelings included upset, stress and anger and sometimes they felt unable to cope.

"It buried up inside me." (Christine, age 14)

"Erm, it's been difficult because, erm, sometimes it just makes me upset and stuff." (Cara, age 16)

"I think I could take it all but then there were times when it would sort of play a toll on me... it's just so much that I shouldn't have to deal with...” (Amy, age 18)

“...that really stressed me out so then, when I went home to my parents they'd be like, 'why are you so angry, why are you so annoyed, why are you so stressed?'...” (Sally, age 18)

Cara's repetition of the word 'erm' conveys hesitation, showing how difficult it was for young people to talk about their own feelings. Amy's reference to it playing 'a toll' suggests the weight of it was damaging to her at times. Her comment that it was 'so much that I shouldn't have to deal with' illustrates a feeling of unfairness that she was left burdened with it. Sally's quotation highlights how other important people in her life began to notice changes in her presentation.

Rachel was reaching a point where she could no longer handle it and individuals in Cara's wider friendship group suffered a powerful emotional impact.

"Sometimes I couldn't cope one day with it and it was getting a bit too much..." (Rachel, age 17)

"Yeah, one of the friends she told, she used to go home and like cry because it's hurt her." (Cara, age 16)

For others, they were left more with a feeling of discomfort.

"Erm, it's a little bit, um, uneasy." (Ann, age 15)

"I didn't really like it, I don't really like it now because it's not a nice thing to do." (Jodie, age 13)

\section{Superordinate Theme 3: Too Hot to Handle}

This theme reflects that participants sensed they were dealing with something risky, so wanted their friend's self-harm to end. Nearly all struggled with whether or not they should tell others, presenting a dilemma about whether to seek help.

\section{This is not Going to End Well}

The majority of participants carried a heavy worry that their friend's behaviour might escalate to something more serious, including ending their life. 
"I was just like, this is not gonna end well." (Christine, age 14)

"I just didn't want it to go too far cause I know sometimes people cut too deep and go to hospital." (Amy, age 18)

"If someone is doing it then they need to go and get help, because it could lead them to something bigger and they could end up in hospital if something bad happens."

(Alex, age 13)

Amy's quotation highlights her need to intervene before it went 'too far'. Alex's use of the words, 'something bigger' and 'something bad', indicates she knew it could result in an escalation of physical harm, but she simply could not bring herself to say it out loud. Her comment that 'they need to go and get help' suggests she wanted to be rid of the responsibility.

Rachel worried that it would get 'worse and worse', conveying her dread in terms of what could happen next.

"I was kind of worried that it would get worse and worse and I'd end up losing her because that's just automatic where my mind went. At that point all I thought was like, self-harm, self-harm, suicide..." (Rachel, age 17)

Sally wanted to talk to her friend about her concerns but was terrified this in itself might cause her friend to do something 'ridiculous'; she couldn't bear being blamed.

"Yeah so obviously like me being me, I can't ever say anything, like any of this to her because like thing is, she might take that as a 'oh my god...' and then go and do something ridiculous... and then I'd be like, that was my fault." (Sally, age 18)

\section{Will Say Nothing to Anyone Unless I need to}

Participants grappled with whether or not to break their friend's trust and tell someone about their self-harm. They were stuck in a dilemma, wanting to stay loyal yet also wanting support for their friend and themselves. Jodie highlights how this trust allowed her friend to open up.

“They open up like, because I won't say nothing to anyone unless I need to, so they open up to me..." (Jodie, age 13)

For Ann and Amy, loyalty initially took president over telling others.

"I have to keep it, you know, don't stress anybody out because they might not come to me anymore and I'm like in the dark, you know like, in the shadows." (Ann, age 15)

"I didn't feel like I should tell anyone else due to confidentiality, just because again, we did not have many friends and I didn't want to sort of just spread it around... no one else knew, it was just between us." (Amy, age 18)

Ann's reference to being 'in the shadows' if her friend chose not to confide in her anymore suggests she wanted to be in the know, perhaps so that she could still be there to provide support, but also because she felt a sense of importance that she was the chosen confidant. This worry highlights that this dilemma could lead to the loss of a protective factor for some individuals. Amy's quotation also indicates a sense of importance; her reference to keeping her friend's self-harm 'just between us' indicates their relationship was now bound by a special bond. She may have also held this relationship in even greater esteem because they were not part of a wider friendship group. 
Cara conveys just how tricky the dilemma was, requiring her to tread carefully.

"Some of it, erm, she's told me not to like, tell the teacher or anything, so I just told things that she's not told me to not tell." (Cara, age 16)

Jodie, like many others, could only deal with knowing so much before reaching a point of needing to tell someone. She shows awareness of her limitations.

"I did tell her that obviously she'd have to tell someone in her family, like not just keep telling me because the more she tells me, the more like, the more it's gonna make me like need to tell someone." (Jodie, age 13)

Over time all except for Amy broke their friend's trust. When participants were able to do so, it meant further support was gained for their friend and themselves.

"I told the teacher and she said she's gonna help her to stop doing it and stuff." (Cara, age 16)

"My mate knew that I was doing this but I would kind of start talking to my mum or my brother or my brother's girlfriend, because she went through self-harm...” (Rachel, age 17)

In cases where others in the wider friendship group were aware, they too, sought support for their friend.

“...so they've done exactly the same what I did, to tell the teacher." (Cara, age 16)

“... and that person said, I can't hide that.” (Rachel, age 17)

\section{Stop Please}

Participants desperately wanted their friends to stop self-harming and for some, this meant giving their undivided attention.

"I just felt like, you know, stop please." (Amy, age 18)

"Well we did FaceTime a lot, so like her phone's constantly moving so I could see the full thing so she couldn't cut or nothing..." (Jodie, age 13)

"Whilst I'm there if he does something it'll be, it'll be like I haven't done anything to stop it. So I feel like I have to, I want, I want to be like making sure that he's not doing anything so I don't have anything to feel bad about." (Alex, age 13)

Jodie's quotation shows the level of vigilance participants thought they needed to adopt. Alex's change in words from 'I have to' to 'I want to' suggests she was trying to convince herself that she was happy to help her friend but really underneath, she felt obliged. She believed she would be to blame if he did anything whilst she was with him.

For Rachel, there was a sense that she didn't want her friend to be associated with something like self-harm, so she acted by trying to build up her self-esteem as a way to persuade her not to do it.

"If she was like, 'I want to self-harm', I'd try and talk her out of it, I'd be like,

'you know you're better than this', and all that lot...” (Rachel, age 17) 


\section{Superordinate Theme 4: Identification}

For some participants, self-harming behaviours pushed them further apart whereas for others, they felt more connected to their friend.

\section{Not the Person I Knew}

After discovering their friend's self-harm, many participants re-evaluated their friendship, feeling disconnected from the friend they thought they knew and unable to identify with them.

"It just didn't seem like the (name of friend) that I knew." Christine, age 14.

"The first time they surprised me because they didn't seem like that person to do such

a thing..." (Jodie, age 13)

"I was so shocked when I found out, because I thought X would never do that, I didn't think he was that type of person." (Alex, age 13)

"She wasn't one to show off, she wasn't one of these people that like, did it for attention.” (Amy, age 18)

These quotations indicate some participants had a stereotyped view of someone who self-harms, highlighting the stigma that still surrounds the behaviour.

For some, the sense of disconnect drove them apart.

"That would drive a wedge between us quite a lot of the time..." (Sally, age 18)

\section{Know Exactly where you are Coming from}

For other young people, they felt a greater connection with their friend through being able to relate to their situation and subsequently, most became closer.

"I know what it's like to not have a good family life at times..." (Amy, age 18)

"Eight all became a lot closer because we, we'd understand kind of people's backgrounds and stuff...because people were like, 'oh I know exactly where you're coming from'..." (Rachel, age 17)

Rachel's quotation highlights this connection was felt throughout her whole friendship group.

For Alex, she found her own comfort through being able to identify with her friend's experience, relieved she was no longer on her own with self-harm after years of keeping it to herself.

"I related to... I mean of course, I wasn't fifteen, I was only ten but erm, I felt like I wasn't the only person, like I wasn't alone in it...” (Alex, age 13)

Although this provided her with some comfort, it also took her back to a painful time in her own life. This spurred her on to help her friend, so that he would not have to go through what she experienced.

"I used to do it in year five, so I know how he feels... I honestly had the worst time of my life and I didn't want anyone else feeling like that..." (Alex, age 13) 


\section{Feeling Invalidated}

For one young person, her friend's self-harm was so different to her own that it invalidated her experience of the behaviour. She strongly believed her friend started self-harming because she was doing it, which frustrated her because she thought her friend had no real grounds for the behaviour, whereas she depended on it.

"Like, obviously she was able to switch on and off this when she decided to be like, depressed, type thing, and when she would self-harm, whereas I was relying on it weekly, like daily." (Sally, age 18)

"She'd never do it, like she'd never cut so that it left a scar, it would always be like the tiniest, like, miniscule thing..." (Sally, age 18)

"Then it turned into my friend being like, 'oh, she's the one who self-harms', because I wasn't there... so it was kind of like she was trying to fill a position." (Sally, age 18)

Sally's reference to her friend switching her self-harm 'on and off' compared to her reliance suggests she didn't believe it was legitimate. Her comment that her friend would 'never cut so that it left a scar' indicates a sense that her friend could not match the extent of her self-harm. Her reference to her friend trying to 'fill a position' conveys the level of threat the behaviour presented to her own sense of self, particularly in the context of her wider peer group, where she described how over time she became more isolated from her other friends. In order to cope, and perhaps in an attempt to categorise herself differently, she would self-harm more. Although Sally was the only person with this experience, one other participant mentioned that she had previously self-harmed (Alex) and others (Ann, Jodie, Rachel) mentioned that people in their friendship group were also self-harming.

\section{Discussion}

The aims of this study were to explore the experiences of adolescents who have a friend who self-harms and to understand what this means for friendship, the wider peer group and psychological well-being. Four superordinate themes were identified: desperately searching for meaning, I will be there at all costs, too hot to handle and identification. These summarise how adolescents make sense of their experience; the lengths they are willing to go to for their friend; the dilemma they face in relation to managing risk and help-seeking and the effects of self-harm on them and their relationship. Previous research relating to this area has largely been quantitative so, to date, there is very little literature which has sought to explore the friend's experience. Therefore this study makes an incremental advance in contributing to and increasing the existing knowledge in this area, highlighting the interpersonal function and effects of self-harm amongst adolescents in the community.

As humans, we have a need to understand what is going on because it enables us to act when our world changes (Weick et al., 2005) and provides us with a sense of control (Grawe, 2007). This may explain why young people were desperately trying to find meaning for their friend's behaviour as this may have actually provided a way to cope. Initially some participants struggled with this, which could be due to self-harm still being a taboo subject, meaning young people may be naive to self-harm until faced with it because it is seen as something that should not be talked about. This was also apparent in the subordinate theme 'not the person I knew', which showed that some participants had a stereotyped 
view of people who self-harm. Given that six schools declined to take part in this research due to concerns about an adolescent population talking about self-harm, or because they feared parents may worry that self-harm was a problem at their school, it is likely that adults are indirectly reinforcing this stigma to young people, highlighting a much wider systemic issue within UK culture.

The theme 'I will be there at all costs' reflects the overwhelming sense of duty participants felt which took president over everything else and echoes previous research findings (Reichardt, 2016). Participants thought they had no choice but to take on this responsibility, possibly because during adolescence friends become more important for emotional support than parents (Bukowski et al., 1998), so young people may see it as their role to be there for their friend in times of need. Taking on this role could also have been driven by 'empathic concern'; the need to relieve another person's suffering; considered to be important in close friendships (Bukowski et al., 1998,), which all participants described prior to finding out about their friend's self-harm. However, this appeared to develop into 'empathetic distress', when individuals are unable to detach from another person's suffering (Smith \& Rose, 2011), which is comparable to 'compassion fatigue' (Figley, 1995), often experienced by helping professionals. This has been found to be something which females experience in particular (Kessler \& McLeod, 1984), likely because female friendships involve more disclosure, support and closeness (Rose \& Rudolph, 2006), supporting the findings of this study and those found by Fisher et al. (2017). Participants experienced worry and distress in the form of upset, stress and anger, mirroring emotions parents have experienced upon finding out about their child's self-harm (Ferrey et al., 2016).

Self-harm was 'too hot to handle' for the majority of these young people. The concern that their friend's behaviour might escalate compounded their distress and eventually this worry, combined with the weight of being the confidant, became too much to bear for almost all. This ultimately led to gaining vital support for their friend, reflecting previous research that friends have an important supportive role (Idenfors et al., 2015). However, some participants felt special that they were the chosen confidant, so initially, tended not to gain additional support. Therefore, young people may be less likely to seek support for their friend if they could lose not only what they consider to be an important friendship, but also their own sense of importance.

Within the theme of 'identification', some young people felt a greater connection to their friend and consequently became closer following the disclosure, which fits with existing research that following self-harm, adolescents experience better relationships with their peers (Snir et al., 2018). However, others felt an initial disconnect and one participant had quite a different experience to everyone else. This participant saw her friend's self-harm differently in comparison to her own, as superficial and minimal. Research suggests that young women engaging in superficial self-harm need a non-judgemental relationship as part of their recovery (Ryan et al., 2008), so her response may have influenced her friend's on-going behaviour. Although it is not clear whether or not her friend's self-harm was a direct result of her own, this finding is consistent with other research (Hawton et al., 2006; Prinstein et al., 2010; You et al., 2013).

Furthermore, there were reports from other participants that individuals in their friendship groups were self-harming, indicating that some self-harm may be influenced by observing the behaviour of others (Nock, 2009) and could be socially motivated, or initiated based on the perceived benefits of its use as a coping strategy in times of distress. This emphasises the risks to peers exposed to a friendship of this nature and how young people may try to achieve a sense of belonging within their peer group. It may be the quality of the relationship that increases the risk for engagement in self-harm, based on previous research 
that has found for adolescents, a best friend's engagement in self-harm is the strongest predictor of their own (You et al., 2013). However, this was unclear.

In relation to participants' wider peer groups, the results highlight that empathetic distress can extend beyond the initial confidant, yet the wider group can also act as a protective factor by sharing out the responsibility. However for one participant, others in her friendship group knowing about her friend's self-harm meant she actually became more isolated from them because she experienced this as a threat to her position within the peer group. Thus, for her this meant the loss of a protective factor, not only in relation to sharing the burden of her friend's self-harm, but also in relation to her own self-harm.

\section{Clinical Implications}

As this study is of a small-scale, caution needs to be applied when offering changes to practice. However, the results have implications for self-harm interventions for young people, families, schools/colleges, mental health staff and other frontline professionals working in young people's services. As many of the participants struggled to make sense of their friend's self-harming behaviour and worried about the potential for it to worsen, young people would benefit from education on self-harm including spotting early warning signs and recognising signs of when it may be escalating. For example, increasing awareness of the risk and protective factors associated with suicide so that young people know how to respond in a crisis. This could be achieved through something like the Youth Aware of Mental Health (YAM) programme; a school-based intervention recently commissioned by the Department for Education for year 9 pupils in the UK, which aims to raise awareness of mental health whilst increasing young people's knowledge and skills. It has a particular emphasis on empathy towards others and has been found to improve young people's confidence in supporting a friend in need (Wasserman et al., 2018).

Young people who find themselves supporting peers with self-harm would benefit from being educated on the effects of this role on friendship, the wider peer group and psychological well-being. Raising their awareness of this is important in order to normalise their experiences so that they do not feel alone in managing it, given the great sense of responsibility and distress highlighted by study participants. Parents, schools/colleges, mental health professionals and other frontline staff would also benefit from this, along with being given guidance so that they can best support these individuals. For example, using approaches such as non-judgemental listening and helping them to manage risk. Something such as Youth Mental Health First Aid training could be offered; it aims to teach adults skills to support adolescent mental health and initial evaluation of the programme suggests it improves knowledge, attitudes and helping behaviour (Kelly et al., 2011). However, this support relies on young people being able to disclose to adults in the first place, which many of the participants in this study found themselves in a dilemma about.

Therefore, schools and colleges should promote and model talking about mental health openly in order that young people feel able to do the same, which may lead to further opportunities for disclosures and help seeking. Although it is recommended that all schools should establish an environment which promotes young people's well-being (Children's Commissioner, 2017), given the response from some schools in relation to taking part in this research, it is apparent that there is still a long way to go. If schools have a culture of not talking about mental health difficulties such as self-harm, perhaps perceiving it to be shameful, this may reinforce a young person's view, and the view of their friends, that it is not ok to talk about and perpetuate the sense of shame they may feel. This may shut down 
any opportunities for the young person, or for their friends, to gain support and reinforce to the school that support is not needed. In the most recent Green Paper (Department of Health and Department for Education, 2017) one of the main aims is for every school and college to have a designated mental health lead by 2025; someone who is responsible for their school's approach to mental health. If this was achieved and whole school initiatives were implemented promoting openness in relation to talking about mental health, young people would be more likely to be able to gain the support they need.

All the participants in this study experienced their own distress and therefore, interventions offered to young people supporting a friend with self-harm could include developing skills in self-care. Furthermore, as nearly all were in a dilemma about whether or not to break their friend's trust and seek help from those around them, signposting them to other available support, such as online forums or telephone helplines, would be beneficial and could also help to prevent them from engaging in self-harm themselves. Mental health professionals need awareness of the role of peers in relation to young people they may be working with who self-harm and consider what other interventions could be offered to both that young person and to their friend; one possibility could be group work. More recently in the UK there has been a focus on the majority of NHS mental health spending going towards those with the most severe needs (Children's Commissioner, 2017); however the results of this study highlight that putting more emphasis on primary mental health work for adolescents would be of great benefit.

\section{Limitations and Future Research}

In IPA studies only a small sample of participants is required as breadth is sacrificed for depth (Smith \& Osborn, 2008). Although the research generated rich data, it was noted the interviews were all quite short in length. While this may reflect the stigma still surrounding self-harm, it could have affected the level of depth the researcher was able to achieve. Furthermore, although only a small sample was needed, the participants in this study were all from the North West of England, all female and all white except one, so a more representative sample would have been preferable. However, it is acknowledged that female relational style encompasses more disclosure and a stronger interpersonal engagement than that of male (Rose \& Rudolph, 2006) and therefore it is perhaps not surprising that all were female. Furthermore, all except one spoke about a female friend and it has been found that girls often show a preference for same-sex friendships (Bukowski et al., 1999).

In one of the schools, recruitment was aided by staff speaking directly to students they knew were eligible, so it is possible that there was some selection bias. This may mean some participants were more willing to talk about their experiences and therefore, more likely to have sought help for their friend from others, possibly influencing some of the results. Given that the UK is an individualistic country, the findings may only be able to be generalised to countries with a similar culture.

Future research could include adolescents from a wider area of the UK with more diversity in terms of gender and cultural background, to determine whether there are any gender or cultural differences with regard to a friendship of this nature. It would also be interesting to explore whether there are any differences in this type of friendship between people living in more collectivist societies. Additionally, as friendship quality may be the biggest risk for a friend's engagement in self-harm (You et al., 2013), further exploration of what it is about closeness in the relationship that may particularly increase the risk is warranted. 


\section{Conclusions}

To conclude, this study explored how adolescents who have a friend who self-harms made sense of this experience. Eight adolescents were interviewed and their data was analysed using IPA. Four superordinate themes were identified: desperately searching for meaning, I will be there at all costs, too hot to handle and identification. These results highlight the important role of the friend in supporting adolescents who self-harm but also the need for greater support for these individuals, particularly psychological support and guidance on managing this role. Schools/colleges should educate young people about self-harm to increase their knowledge and skills in relation to supporting a friend with this issue and promote environments for talking about mental health openly to give young people increased opportunities for help-seeking. Future research could include a more diverse sample of adolescents from a larger area of the UK.

Funding The authors did not receive support from any organization for the submitted work. No funding was received to assist with the preparation of this manuscript. No funding was received for conducting this study. No funds, grants, or other support was received.

\section{Declarations}

Conflict of interest The authors declare they have no conflict of interest.

Ethical approval Ethical approval was obtained from Staffordshire University Ethics Committee. As participants were between 13 and 18 years of age, parents of those under 16 years old were given the choice to opt out their child from taking part.

Informed consent Informed consent was obtained from all individual participants included in the study. Participants were informed of their right to withdraw, debriefed and signposted to sources of support where appropriate. Participants were also asked some additional questions at the end of the interview relating to risk and were told that if they disclosed any serious concerns about themselves or their friend, confidentiality would be broken and concerns passed on to the appropriate people. All participants were given a pseudonym to preserve anonymity.

\section{References}

Armiento, J. S., Hamza, C. A., \& Willoughby, T. C. (2014). An examination of disclosure of non-suicidal self-injury among university students. Journal of Community \& Applied Social Psychology, 24, $518-533$.

Berger, P. L., \& Luckmann, T. (1996). The social construction of reality: A treatise in the sociology of knowledge. Hamondsworth, Middlesex: Penguin Education.

Brunner, R., Kaess, M., Parzer, P., Fischer, G., Carli, V., Hoven, C. W., Wasserman, C., Sarchiapone, M., Resch, F., Apter, A., Balazs, J., Barzilay, S., Bobes, J., Corcoran, P., Cosmanm, D., Haring, C., Iosuec, M., Kahn, J. P., Keeley, H., ... Wasserman, D. (2014). Life-time prevalence and psychosocial correlates of adolescent direct self-injurious behaviour: A comparative study of findings in 11 European countries. Journal of Child Psychology and Psychiatry, 55(4), 337-348.

Bukowski, W. M., Newcomb, A. F., \& Hartup, W. W. (1998). The company they keep: Friendships in childhood and adolescence. Cambridge University Press.

Bukowski, W. M., Sippola, L. K., \& Hoza, B. (1999). Same and other: Interdependency between participation in same and other sex friendships. Journal of Youth and Adolescence, 28(4), 439-459. 
Children's Commissioner (2017). Briefing: Children's Mental Healthcare in England. https://www.child renscommissioner.gov.uk/wp-content/uploads/2017/10/Childrens-Commissioner-for-England-Mental-Health-Briefing-1.1.pdf Accessed March 72019.

Claes, L., Houben, A., Vandereycken, W., Bijttebier, P., \& Muehlenkamp, J. (2010). Brief report: The association between non-suicidal self-injury, self-concept and acquaintance with self-injurious peers in a sample of adolescents. Journal of Adolescence, 33, 775-778.

Department of Health \& Department for Education. (2017). Transforming children and young people's mental health provision: A green paper. Department of Health and Department for Education.

Ferrey Anne, E., Hughes, N. D., Simkin, S., Locock, L., Stewart, A., Kapur, N., Gunnell, D., \& Hawton, K. (2016). The impact of self-harm by young people on parents and families: A qualitative study. British Medical Journal, 6(1), 1-7.

Figley, C. R. (1995). Compassion fatigue as secondary traumatic stress disorder: An overview. In C. R. Figley (Ed.), Compassion fatigue: Coping with secondary traumatic stress disorder in those who treat the traumatised (pp. 1-20). Brunner-Routledge.

Fisher, K., Fitzgerald, J., \& Tuffin, K. (2017). Peer responses to non-suicidal self-injury: Young women speak about the complexity of the support-provider role. New Zealand Journal of Psychology, 46(3), 146-155.

Fortune, S., Sinclair, J., \& Hawton, K. (2008a). Adolescents' views on preventing self-harm: A large community study. Social Psychiatry and Psychiatric Epidemiology, 43(2), 96-104.

Fortune, S., Sinclair, J., \& Hawton, K. (2008b). Help-seeking before and after episodes of self-harm: A descriptive study in school pupils in England. BMC Public Health, 8, 369.

Grawe, K. (2007). Neuropsychotherapy: How the neurosciences inform effective psychotherapy. Routledge.

Hasking, P., Rees, C. S., Martin, G., \& Quigley, J. (2015). What happens when you tell someone you self-injure? The effects of disclosing NSSI to adults and peers. BMC Public Health, 15, 1039.

Hawton, K., Rodham, K., \& Evans, E. (2006). By their own young hand. Deliberate self-harm and suicidal ideas. Jessica Kingsley.

Hawton, K., Rodham, K., Evans, E., \& Weatherall, R. (2002). Deliberate self-harm in adolescents: Selfreport survey in schools in England. British Medical Journal, 325, 1207-1211.

Heath, N. L., Toste, J. R., Sornberger, M. J., \& Wagner, C. (2011). Teachers' perceptions of non-suicidal self-injury in the schools. School Mental Health, 3(1), 35-43.

Idenfors, H., Kullgren, G., \& Renberg, E. (2015). Professional care as an option prior to self-harm: A qualitative study exploring young people's experiences. Crisis, 36(3), 179-186.

Kelly, C. M., Mithen, J. M., Fischer, J. A., Kitchener, B. A., Jorm, A. F., Lowe, A., \& Scanlan, C. (2011). Youth mental health first aid: A description of the program and an initial evaluation. International Journal of Mental Health Systems, 5(4), 1-9.

Kessler, R. C., \& McLeod, J. D. (1984). Sex differences in vulnerability to undesirable life events. American Psychological Review, 49, 620-631.

Klonsky, E. D. (2007). The functions of deliberate self-injury: A review of the evidence. Clinical Psychology Review, 27(2), 226-239.

Klonsky, E., \& Olino, T. M. (2008). Identifying clinically distinct sub-groups of self-injurers among young adults: A latent class analysis. Journal of Consulting and Clinical Psychology, 76(1), 22-27.

Koch, T., \& Harrington, A. (1998). Reconceptualizing rigour: The case for reflexivity. Journal of Advanced Nursing, 28(4), 882-890.

Madge, N., Hewitt, A., Hawton, K., Jan, E., de Wilde, P., Corcoran, S. F., van Heeringen, K., De Leo, D., \& Ystgaard, M. (2008). Deliberate self-harm within an international community sample of young people: Comparative findings from the Child \& Adolescent Self-harm in Europe (CASE) Study. Journal of Child Psychology and Psychiatry, 49(6), 667-677.

Morgan, C., Webb, R. T., Carr, M. J., Kontopantelis, E., Green, J., Chew-Graham, C. A., Kapur, N., \& Ashcroft, D. M. (2017). Incidence, clinical management, and mortality risk following self-harm among children and adolescents: Cohort study in primary care. British Medical Journal, 359, 4351.

National Institute for Health and Care Excellence [NICE] (2013). Self-harm: Quality standard. Retrieved March 10, 2021 from: https://www.nice.org.uk/guidance/qs34/resources/selfharm-pdf-2098606243 525.

Nock, M. K. (2009). Why do people hurt themselves? New insights into the nature and functions of selfinjury. Current Directions in Psychological Science, 18(2), 78-83.

Osborn, M., \& Smith, J. A. (1998). The personal experience of chronic benign lower back pain: An interpretative phenomenological analysis. British Journal of Health Psychology, 3, 65-83.

Pachankis, J. E. (2007). The psychological implications of concealing a stigma: A cognitive-affectivebehavioural model. Psychological Bulletin, 133(2), 328. 
Prinstein, M. J., Heilbron, N., Guerry, J. D., Franklin, J. C., Rancourt, D., Simon, V., \& Spirito, A. (2010). Peer influence and nonsuicidal self injury: Longitudinal results in community and clinically-referred adolescent samples. Journal of Abnormal Child Psychology, 38(5), 669-682.

Rabinow, P., \& Sullivan, W. (1987). Interpretive social science. A second look. Berkeley.

Reichardt, J. (2016). Exploring school experiences of young people who have self-harmed: How can schools help? Educational and Child Psychology, 33(4), 28-39.

Rodham, K., Hawton, K., \& Evans, E. (2004). Reasons for deliberate self-harm: Comparison of selfpoisoners and self-cutters in a community sample of adolescents. Journal of the American Academy of Child and Adolescent Psychiatry, 43, 80-87.

Rose, A. J. (2002). Co-rumination in the friendships of girls and boys. Child Development, 73, $1830-1843$.

Rose, A. J., \& Rudolph, K. D. (2006). A review of sex differences in peer relationship processes: Potential trade-offs for the emotional and behavioural development of girls and boys. Psychological Bulletin, 132, 89-131.

Rose, A. J., Carlson, W., \& Waller, E. M. (2007). Prospective associations of co-rumination with friendship and emotional adjustment: Considering the socioemotional trade-offs of co-rumination. Developmental Psychology, 43, 1019-1031.

Rowe, S. L., French, R. S., Henderson, C., Ougrin, D., Slade, M., \& Moran, P. (2014). Help-seeking behaviour and adolescent self-harm: A systematic review. The Australia and New Zealand Journal of Psychiatry, 48(12), 1083-1095.

Ryan, K., Heath, M. A., Fischer, L., \& Young, E. L. (2008). Superficial self-harm: Perceptions of young women who hurt themselves. Journal of Mental Health Counselling, 30(3), 237-254.

Sakinofsky, I. (2000). Repetition of suicidal behaviour. In K. Hawton \& K. Van Heeringen (Eds.), The international handbook of suicide and attempted suicide (pp. 385-404). John Wiley \& Sons.

Smith, R. L. (2015). Adolescents' emotional engagement in friends' problems and joys: Associations of empathetic distress and empathetic joy with friendship quality, depression, and anxiety. Journal of Adolescence, 45, 103-111.

Smith, J. A., \& Osborn, M. (2008). Interpretative phenomenological analysis. In J. A. Smith (Ed.), Qualitative psychology: A practical guide to research methods (2nd ed.). Sage.

Smith, J. A., \& Osborn, M. (2015). Interpretative phenomenological analysis as a useful methodology for research on the lived experience of pain. British Journal of Pain, 9(1), 41-42.

Smith, R. L., \& Rose, A. J. (2011). The “cost of caring” in youths' friendships: Considering associations among social perspective taking, co-rumination, and empathetic distress. Developmental Psychology, 47(6), 1792-1803.

Snir, A., Apter, A., Barzilay, S., Feldman, D., Rafaeli, E., Carli, V., Wasserman, C., Hadlaczky, G., Hoven, C. W., Sarchiapone, M., \& Wasserman, D. (2018). Explicit motives, antecedents and consequences of direct self-injurious behaviours: A longitudinal study in a community sample of adolescents. Crisis, 39(4), 255-266.

Swannell, S., Martin, G., Page, A., Hasking, P., \& St John, N. (2014). Prevalence of non-suicidal selfinjury (NSSI) in non-clinical samples: Systematic review, meta-analysis and meta-regression. Suicide and Life-Threatening Behaviour, 44, 273-303.

Taiminen, T. J., Kallio-Soukainen, K., Nokso-Koivisto, H., Kalijonen, A., \& Helenius, H. (1998). Contagion of deliberate self-harm among adolescent inpatients. Journal of the American Academy of Child and Adolescent Psychiatry, 37(2), 211-217.

Wasserman, C., Postuvan, V., Herta, D., Losue, M., Värnik, P., \& Carli, V. (2018). Interactions between youth and mental health professionals: The Youth Aware of Mental health (YAM) program experience. PLoS ONE, 13(2), 1-33.

Webb, C. (2003). Introduction to guidelines on reporting qualitative research. Journal of Advanced Nursing, 42(6), 544-545.

Weick, K. E., Sutcliffe, K. M., \& Obstfeld, D. (2005). Organising and the process of sense making. Organisation Science, 16(4), 409-421.

Whitlock, J., Eckenrode, J., \& Silverman, D. (2006). Self-injurious behaviours in a college population. Paediatrics, 117, 1939-1948.

World Health Organization [WHO] (2018). Adolescent health. http://www.who.int/topics/adolescent_ health/en/ Accessed December 282018.

Yardley, L. (2000). Dilemmas in qualitative health research. Psychology and Health, 15(2), 215-228.

Yip, K. S., Ngan, M. Y., \& Lam, I. (2002). An exploration study of peer influence and response to adolescent self-cutting behaviour in Hong Kong. Smith College Studies in Social Work, 72(3), 379-401. 
You, J., Lin, M.-P., Fu, K., \& Leung, F. (2013). The best friend and friendship group influence on adolescent nonsuicidal self-injury. Journal of Abnormal Child Psychology, 41(6), 993-1004.

Publisher's Note Springer Nature remains neutral with regard to jurisdictional claims in published maps and institutional affiliations. 